\title{
The Psycho-Social Wellbeing of the Teenage Mothers
}

\author{
T. Pitso ${ }^{a}$ \\ J. Kheswa ${ }^{a}$ \\ F. Nekhwevha a \\ M. Sibanda $b$ \\ a Department of Psychology, University of Fort Hare, P. Bag X1314, Alice 5700, RSA. Email: tsoloz2002@yahoo.co.uk \\ ${ }^{b}$ Department of Agricultural Economics and Extension, University of Fort Hare, P. Bag X1314, Alice 5700, RSA
}

Doi:10.5901/mjss.2014.v5n10p610

Abstract

The quantitative study assessed the psychosocial wellbeing of teenage mothers. This report analysed the current positions of women whose first child was to be born when they were teenagers in the rural Eastern Cape Province. The structured questionnaires were administered to 106 pregnant teenagers in clinics around Alice, Eastern Cape. Convenient sampling was used to select respondents. Data was analysed using SPSS version 18.0. Statistical software. Descriptive and inferential statistics were both employed. The binary regression model was used to assess the factors affecting the pregnant teenagers' readiness for motherhood. The psycho-social theory of Erikson posited that children with negative psycho-social development have a high chance of facing identity crisis/confusion. As a result, this might lead to them being victims of psycho-social interaction such as early pregnancy. Both the descriptive and the binary regression results indicated that $79 \%$ of the teenage mothers showed lack of readiness for motherhood, hence their psychosocial wellbeing was negative.

Keywords: Identity-acquisition, Identity-crisis, Psycho-social Wellbeing, Readiness, Teenage motherhood.

\section{Introduction}

According to Lilaroja (2010), motherhood is formally defined as a pregnancy in a young woman who has not reached her 20th birthday when the pregnancy ends, regardless of whether the woman is married or is legally an adult (age 14 to 21 , depending on the country). In everyday speech, the speaker is usually referring to unmarried minors who become pregnant unintentionally. Holborn and Eddy (2011) found out that the rate of teenage motherhood is high in South Africa, with the fertility rate half that of the average Sub-Saharan Africa. This simply means that fertility rate in South Africa is three times higher than the average rate in East Asia and four times higher than the average European rate.

Early motherhood is commonly associated with lower education, reduced labour market participation and poverty. The lower income of teenage mothers possibly affects both their own and their children's economic well-being (Chevalier and Viitanem, 2001).The transition to motherhood is a major event in the lifespan of any individual, but takes on special significance when it precedes the transition to education, work, citizenship and marriage that collectively offer the skills, resources and social stock necessary for individuals to succeed as parents (Panday, Makiwane, Ranchod, and Letswalo, 2009). Teenage fertility establishes the pace and level of fertility over a woman's entire reproductive life span. Furthermore, teenage mothers are often unprepared or too immature to care for a child. Their choices in all aspects of life are restricted. Finally, the suicide rate for pregnant teenagers is ten times than that of the general population (Weiten, Dunn and Hammer, 2012).

For mothers between 15 and 19, additional risks may be associated with socio-economic factors. According to Planned Parenthood Association of South Africa (1998), there could be a higher risk of medical complications if the pregnancy is unsupervised. The following risk could emerge: Difficult labour, a greater chance of caesarian section, premature labour, and birth complications. There could be secondary and tertiary educational deprivation for the pregnant teenager and approximately one half of the girls who give birth before the age of eighteen do not complete schools. As a result, life plans and career goals are disrupted. The girl experiences isolation from her peers.

In addition, due to difficulty in pregnancy, emotional experience could lead to: disappointment, anger, depression, feelings of being trapped, loneliness, anxiety and insecurity.

Chevalier and Viitanem (2001) showed that motherhood is also taken to be a skill which strictly needs effective and 
efficient mothering skills. Macleod (2000) advocated that mothering as a skill involves: Nurturing and unconditional raising of children from prenatal stage up to the late adolescence. The majority of teenage mothers have difficulty in performing mothering role and this is an indication that they did not receive lessons during their prenatal period. The teenage mothers' dependency on adults for norms of parenting and preparation for child care exacerbates difficulties associated with the transition to motherhood.

Furthermore, there has to be a proper awareness that motherhood is a twenty four hour service per day, seven days a week and three hundred and sixty five and quarter days a year. The role and responsibility of motherhood starts from conception until eighteen years at minimum. The teenage mother's total inability to cope may result in high incidence of child abuse, neglect and possible abandonment to the child.

\section{The Problem}

Burns and Grove (2005) define a research problem as a situation in need of a solution, improvement or alteration, a discrepancy between the way things are and the way they ought to be.

Macleod (2000) posited teenage mothers are less knowledgeable about the prenatal and post-natal challenges of parenthood, hence their psychosocial wellbeing is poor. As a result, failure could emerge in performing the roles and responsibilities of motherhood.

\section{Preliminary Literature Review}

Teenage-motherhood could bring a myriad of problems which could be psychological, physiological and socioeconomical. Teenage mothers are unaware of some consequences of early motherhood, namely, poverty, reduced job opportunities and low self-esteem. Teenage -mothers believe that children are important for the security and continuation of the family, family possessions and family name, hence cultural values contribute to non-utilization of condoms when engaging in sexual activities (Ziyane and Ehlers, 2006).

\section{Hypothesis}

According to Dryburgh (2002), a hypothesis is a logical supposition, a reasonable guess, an educated conjecture. It provides a tentative explanation for a phenomenon under investigation. The main hypothesis in this study is that pregnant teenagers are not ready for motherhood.

The hypothesis of this study could be highlighted as follows:

H1: Pregnant Teenagers display higher levels of parenting stress and are less responsive and sensitive in interactions with their infants than are adult mothers, hence they are not psychosocially well.

\section{The Research Question}

Prompted by the above exposition, the research questions were formulated:

- What is the psycho-social wellbeing of pregnant teenagers?

\section{Research Aim and Objective}

The main aim of this study is to determine psychosocial wellbeing of teenage mothers in the Nkonkobe municipality. The objectives of this study are as follow:

- To determine the psycho-social wellbeing of pregnant teenagers.

\section{Theoretical Framework}

The studies focused on Erikson's theory of psychosocial development and specifically dwelled on the identity versus identity confusion developmental stage, which addresses the psychosocial development of the youth/ teenagers. This stage is between childhood and adulthood and normally, this is the school-going stage. The teenagers experience puberty and the uncertainty of the adult roles ahead. Teenagers are sometimes preoccupied with other people's perceptions about them. This stage is characterized by teenagers exploration and being resourceful in order to acquire identity (Weiten, 2011). Identity refers to a stable sense of knowing who one is and what one's values and ideals are. In 
contrast, identity confusion occurs when the individual fails to develop a coherent and enduring sense of self and has difficulty committing to roles, values, people, or occupational choices. In this regard, pregnant teenagers are more inclined to experience identity- confusion, which may be exacerbated by substance use, domestic violence and lower self-esteem this brings a concern to their psychosocial wellbeing (Leiononnen et al., 2003).

In addition, Kipp and Shaffer (2010) are of the view that for a child to reach the adolescent stage (Identity vs. identity confusion) effectively and efficiently, he or she should undergo the first four psychosocial stages successfully. As a result, the formation of identity will emerge. According to Macleod (2000) the theory shows that the absence of experiences and skills leading to the development of trust, autonomy, skills provision, initiative, encouragement and industry motivation in the early childhood stages by the caregiver to the child may lead to identity confusion to this offspring during adolescence. As a result, the adolescent is more likely to have a low self-worth, low self-esteem, lash out and be defiant towards parent, teachers or any other authority figure.

The theory gives a deep perspective into the psychological effects that can affect a child at different stages of life and the high probability of inter-generational crisis of teenage motherhood. As a result, this paves way to difficulty in playing the roles and responsibility of motherhood.

\section{Literature Review}

\subsection{Psychological and Psycho-social Well-being of Teenage Mothers}

According to Ryff and Keyes (1995), the Ryff Scales of Psychological Well-Being is defined as a dynamic concept that includes subjective, social, and psychological dimensions as well as health-related behaviours. Furthermore, it is an instrument that is theoretically grounded and specifically focuses on measuring the following facets of multiple psychological well-being:

\subsubsection{Self-acceptance}

This denotes resilience and the state of being congruent to what one has and one can do without being a victim of prejudice and discrimination. Furthermore, this means that one is in possession of self-acknowledgement towards ones good and bad qualities and acceptance of one's past experience (Compton and Hoffman, 2013). According to Markway and Markway (2011) most of the teenage mothers are faced with a challenge of accepting themselves due to their negative upbringing which had an impact on their acknowledgement self-value and self-acceptance. As a result, they become victims of exploitation, premature sexual intercourse and unwanted pregnancy.

\subsubsection{Positive relationships}

This is the possession of a conducive interpersonal relationship with others without any opportunistic mentality. It allows the element of trust, loyalty, and empathy to reign. A lack of emotional attachment and bonding between educators and teenage mothers as their loco-parentis, may result in projecting anger towards their children (Papalia et al., 2009).

\subsubsection{Autonomy}

This means that one has to set goals, and have the way to achieve them with a sound decision-making irrespective of negative pressures from the peers and the people around. However, research by Holborn and Eddie (2011) found that the poor socio-economic background and lack of necessary skills of the teenage mothers impede them to be autonomous and gain a sense of independence in order to face everyday challenges.

\subsubsection{Environmental mastery}

Being resilient and having a stalwart backbone to adapt to a multitude of pressures without losing focus and turning those pressures into opportunities for the acquisition of one's goals and aspirations (Compton and Hoffman, 2013).Teenage mothers lack necessary skills in turning the so-called crisis or personal mistakes into a life learned experience which might impede the prognosis of intergenerational vicious-cycle of teenage motherhood (Compton and Hoffman, 2013). 


\subsubsection{Purpose in life}

The state of personal knowledge and acceptance bring about a clear sense of self, in terms of the needs, wants, goals and aspirations (Compton and Hoffman, 2013). This calls for teenage mothers to be aware of who they are so that they can understand their goals and their significance in life but in most cases their lack of proper education and appropriate life skills forbids them to live their expected life (Compton and Hoffman, 2013).

\subsubsection{Personal growth}

The proper self- management with a clear meaningful goals and a sense of purpose in life will bring about intrapersonal and interpersonal growth and development (Compton and Hoffman, 2013). For teenage mothers to grow and develop, they need proper mentoring, and basic education which will open the doors to their acquisition of their dream and goals. Growth and development are life-long journey (Compton and Hoffman, 2013).

\section{Research Design and Methodology}

\subsection{Quantitative Design}

The researcher chose a quantitative research design to assess The Psychosocial Well-being of Teenage Mothers and described it as a procedure for collecting, analysing and interpreting data obtained using validated psychological measuring instruments from a relatively large group of participants (Creswell, 2011). This study attempted to quantify the psychosocial wellbeing of teenage mothers in Nkonkobe Municipality, Eastern Cape. Quantitative data can be transposed into numbers, in a formal, objective, systematic process to obtain information and describe variables and their relationships (Brink 2006). Quantitative research has the following characteristics (Burns and Grove 2005; Brink 2006). There is a single reality that can be defined by careful measurement. It is usually concise. It describes and examines relationships, and determines causality among variables, where possible. Statistical analysis is conducted to reduce and organise data, determine significant relationships and identify differences and/or similarities within and between different categories of data. The sample should be representative of a large population. Reliability and validity of the instruments are crucial and provided an accurate account of characteristics of particular individuals, situations or groups (marital status, age, level of education, socio-economic status, and description of the participants' caregivers, thus biographical information.

\subsection{Descriptive and inferential statistics}

This study was descriptive and explorative in that the researcher collected detailed descriptions of the factors that contributed to the teenage pregnancy rate and the level of these teenage mothers psychosocial wellbeing. The factors identified were described accurately. According to Burns and Grove (2005) the purpose of descriptive research is to provide the opinions of respondents regarding the phenomenon being studied. Descriptive research provides an accurate portrayal or account of the characteristics of a particular individual event, or group in real-life situations for the purpose of discovering new meaning, describing what exists, determining the frequency with which something occurs, and categorising information (Burns and Grove, 2005). Descriptive studies provide valuable baseline information. The method is also flexible and can be used to collect information from a large group of respondents (Brink, 2006). In this study, the researcher attempted to identify and describe factors that contributed to the high pregnancy rate among adolescents and their level of wellbeing in Nkonkobe Municipality, Eastern Cape. According to Brink (2006), an exploratory descriptive research design has the following characteristics: It is a flexible research design that provides an opportunity to examine all aspects of the problem being studied. It strives to develop new knowledge. The data may lead to suggestions or a hypothesis for future studies.

\subsection{Binary Regression Model}

According to Joseph (2010), the binary logistic regression model can be utilised when the dependent variable is not continuous but instead has only two possible outcomes, 1 or 0 . This model is normally used when predicting an event which has two possible outcomes, for example, well to be mothers vs. not well to be mothers.

In this study the dependent variable was pregnant teenagers' readiness for motherhood. In this case, 0 
represented teenage mothers well to be mothers versus 1 which represented pregnant teenagers not well to be mothers. This model was adapted from Desriani (2011) who did a similar study on the analysis of Factors which determine Teenage Motherhood in Indonesia.

\subsection{Population}

Eligibility criteria specify the characteristics that people in the population must possess in order to be included in the study (Babbie and Mouton, 2001). To be included in this study, the respondents had to:

- Be teenage mothers between 11 and 21 years old.

- Be willing to participate in the study.

- Give informed consent.

\subsection{Sampling technique}

A non-probability sampling was used for this study. In non-probability sampling, the population is not known and the researcher does not know the population size Walliman (2005). Teenage mothers between the ages 11-21 were purposively and conveniently selected in this study. Convenience/accidental sampling was employed on the basis of the availability of the respondents.

The expected size of the population of this study was 150 female teenagers (teenage mothers) attending prenatal check up at the clinics in Alice and who are willing to participate voluntarily and complete the questionnaires. A group of 106 teenage mothers represented the population and were available for participating in this study.

\subsection{The Instrument}

The questionnaire was designed to gather information about the factors contributing to teenage pregnancy and the psychosocial wellbeing of the teenage mothers.

The choice of the research instrument (questionnaire) was opted for this study owing to non-direct involvement of the researcher considering the sensitivity of the topic.

\section{Results and Discussion}

\subsection{Descriptive Data}

The hypothesis of this study is highlighted as follow:

$\mathrm{H} 1$ : Pregnant Teenagers display higher levels of parenting stress and are less responsive and sensitive in interactions with their infants than are adult mothers, hence they are not psychosocially well.

Respondents' Level of Education ( $n=106)$

\begin{tabular}{|l|c|c|}
\hline & Frequency & Percentage \\
\hline Pre school & 4 & 3.8 \\
\hline primary & 11 & 10.4 \\
\hline High school & 51 & 48.1 \\
\hline tertiary & 40 & 37.7 \\
\hline Total & 106 & 100 \\
\hline
\end{tabular}

Source: Printout of a table derived from the data of this study

It was important for the researcher to determine the respondents' level of education, as education influences individuals' decisions regarding reproductive issues (3.5.4 Education). Table 5.2 above shows that of the 106 respondents, 3.8\% $(n=4)$ had only pre-school level of education; $10.4 \%(n=11)$ had had a primary school education, $48.1 \%(n=51)$ were attending/had high school education and $37.7 \%(n=40)$ had or are having tertiary education. Table 5.2 indicates that out of 106 pregnant teenagers only 40 which is $37.7 \%$ were in tertiary level while the rest had preschool, primary school and high school education. Muchuruza (2000) found out that teenage motherhood is highly associated with the low level of education and poor socio-economic situation which has a higher chance of intergenerational vicious cycle. 


\subsubsection{Marital status of the respondents' biological parents}

Figure 5.5: Respondents' marital status of the biological parents $(n=106)$

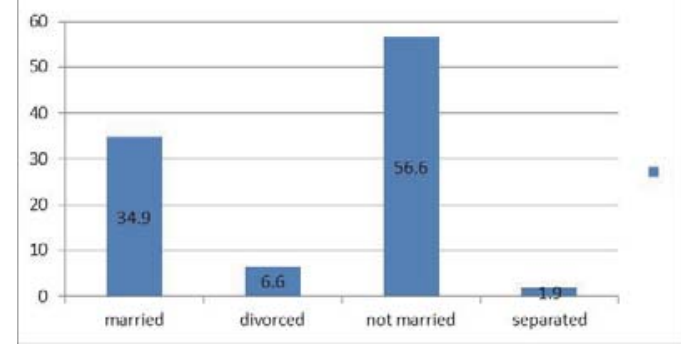

Source: Printout of a table derived from the data of this study

In question 10, the respondents were asked to indicate their biological parents' marital status, as it would indicate the nature of family that the respondents originate from and the influences that such a family can have on the respondents in terms of identity and readiness for motherhood. Figure 5.5 above shows that $34.9 \%(n=37)$ of the respondents parents are married; $6.6 \%(n=7)$ are divorced; $56.6 \%(n=60)$ are not married at all; and $1.9 \%(n=2)$ are separated. The information displayed in figure 5.5 confirms that most of the pregnant teenagers are coming from parents who are not married. According to Hetherington et al., (2006) the attachment theory by Bowlby showed that a family with a single parent can bring imbalance in terms of attachment and upbringing of the off-springs. As a result, children may not develop full psycho-social skills to combat the daily challenges of life.

\subsubsection{Education level of the respondents' parents}

Table 5.4: Education level of the respondents' parents $(n=106)$

\begin{tabular}{|l|c|c|}
\hline & Frequency & Percentage \\
\hline Pre school & 7 & 6.6 \\
\hline primary & 16 & 15.1 \\
\hline High school & 62 & 58.5 \\
\hline tertiary & 21 & 19.8 \\
\hline Total & 106 & 100 \\
\hline
\end{tabular}

Source: Printout of a table derived from the data of this study

According to tables 5.4 of the respondents' parents, $6.6 \%(n=7)$ had Pre-school education; $15.1 \%(n=16)$ had primary school education; $58.5 \%(n=62)$ had high education, and $19.8 \%(n=21)$ had tertiary education. The information provided by the table above shows that $(n=85)$ which make $80.2 \%$ of the parents of the respondents went as far as high school in terms of education and only ( $\mathrm{n}=21$ ) which is $19.8 \%$ managed to get tertiary education. The research by Philemon (2007) found out that the level of education of the parents has an influence on the upbringing of the children and low education means few opportunities for the offspring to survive and vice versa.

\subsubsection{Respondent's readiness to provide child basic need}

Figure 5.8: Respondents provide child's basic need $(n=106)$

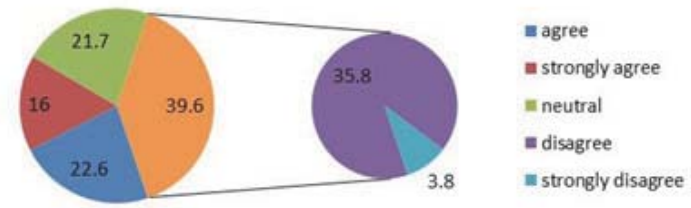

Source: Printout of a figure derived from the data of this study

Figure 5.8 above showed that $22.6 \%(n=24)$ respondents agreed that they were ready to provide the basic needs of their children; $16 \%(n=17)$ strongly agreed that they were ready; while $21.7 \%(n=23)$ were neutral. Furthermore, 35.8\% $(n=38)$ 
disagreed that they were ready to provide the basic needs for their babies; and 3.8\% ( $n=4)$ strongly disagreed that they were ready to provide the basic needs for their babies. The essence of the results is that most of the respondents showed that they were not ready to provide the basic needs for the babies. This might be due to lack of experience and necessary academic qualifications. Philemon (2007) showed that most of the teenage mothers cannot provide the basic needs for their babies because they are dependent on their parents and their occupation should be attending school for the betterment of their brighter future and the future of the countries.

\subsubsection{Respondents inclined to identity confusion after birth $(n=106)$}

Of the 106 respondents, $67 \%(n=71)$ agreed that they were inclined to experience identity confusion after the birth of their baby; $3.8 \%(n=4)$ strongly agreed; $0 \%(n=0)$ were neutral; $15.1 \%(n=16)$ disagreed that they were inclined to experience identity confusion after birth of their baby; and $14.2(n=15)$ strongly disagreed. The findings of this research are that 75 pregnant teenagers were inclined to identity confusion after delivery. Dryburgh (2002) posited that teenage mothers are bound to confusion in playing the roles and responsibilities of motherhood as they lack necessary skills to do so. Hence identity confusion will emerge.

\subsubsection{Physical abuse of the pregnant teenager by the partner $(n=106)$}

Out of 106 respondents, $43.4 \%$ ( $n=46)$ agreed that the father of their children abused them physically; $5.7 \%(n=6)$ strongly agreed; $0 \%(n=0)$ were neutral; as compared to $36.8 \%(n=39)$ who disagreed that the father of their children abused them physically; and $14.2 \%(n=15)$ strongly disagreed. The implication of this finding could be that these pregnant teenagers may come from negative socio-economic background, hence they stay in sexually abusive relationships. It could also be due to financial dependence, hence they are stuck in such relationships. The literature (3.5.16.1 physical and sexual abuse) indicated that the relationship between teenage mothers and their partners is mostly characterised by both physical and sexual abuse whereby the teenage mothers become the victims.

\subsubsection{Relationship between the pregnant teenager and the partner $(n=106)$}

Of the 106 respondents $32.1 \%(n=34)$ agreed that they were in good terms with the father of the child; $17.9 \%(n=19)$ strongly agreed; $0 \%(n=0)$ were neutral; $48.1 \%(n=51)$ disagreed that they were in good terms with the father of the child; and $1.9 \%(n=2)$ strongly disagreed. Drawing from the literature (3.5.15 cohabitation and partner violence), most of the teenage mothers have a negative relationships with their partner and this could go as far as violence or even rape.

\subsubsection{Respondents' friends have children}

Figure 5.15: Respondents friends have children $(n=106)$

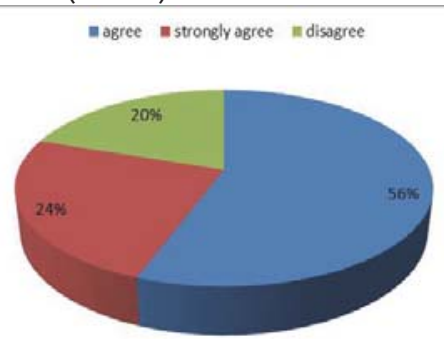

Source: Printout of a figure derived from the data of this study

In this question, the respondent's nature of friends was assessed. Figure 5.15 displays that out of 106 respondents, 56\% $(n=59)$ agreed that their friends had children ; $24 \%(n=26)$ strongly agreed ; $0 \%(n=0)$ were neutral; $20 \%(n=21)$ disagreed that their friends had children; and $0 \%(n=0)$ strongly disagreed. The implication of this finding is that, since $80 \%(n=75)$ of the pregnant teenagers indicated that their friends have children, it is clear that peer pressure is the contributory factor. Gustafsson and Worku (2007) found that peer pressure can also play a major role in deciding when and with whom should the teenage girl have a child. This situation becomes easy when the teenagers are not well mentored by the immediate guardians. 


\subsubsection{Respondent self-confidence $(n=106)$}

In this question, the respondent's level of confidence was assessed. Of the 106 respondents, $25.5 \%(n=27)$ agreed that they were self-confident; and $19.8 \%(n=21)$ strongly agreed. Furthermore, $52.8 \%(n=56)$ indicated that they are not selfconfident; and 1.9\% ( $n=2)$ also strongly disagreed. Easterbrooks et al., (2010) found that most of the teenage mothers are lacking resilience which is defined as the ability to adapt well in the face of adversity, misfortune, tragedy, threats, or even significant sources of stress and are unable to reach the aspired goals. As a result, their self -confidence becomes questionable.

\subsubsection{Caregiver-pregnant teenager's communication $(n=106)$}

Of the 106 respondents, $29.2 \%(n=31)$ agreed that they talk to the caregiver about their problems; and $14.2 \%(n=15)$ strongly agreed. Furthermore, $50.9 \%(n=54)$ revealed that they do not talk to the caregivers about their problems; and $5.7 \%(n=6)$ indicated strongly that they do not talk to their caregivers about their problems. The implication of this finding might be the lack of attachment between the caregivers and the pregnant teenager is due to socio-economic status. According to Baucum (1999) when there is family cohesion, teenagers might be susceptible to some of the negative psycho-social problems such as sustaining relationships.

The findings of this chapter go along with the literature in that, according to the literature, teenage motherhood is characterised by socio-economic challenges, low level of education, dysfunctional families, physical abuse, sexual abuse, rape, low self-esteem, physical and psychological imbalances. According to Santrock (2000) the psychosocial theory of Erikson found that teenagers who were raised from broken families, dysfunctional families, low educational attainment and poor socio-economic background are bound to be subjects of exploitation and are susceptible to psychosocial challenges such as early maternity owing to their identity crisis.

\section{Empirical Data}

The main aim of this study is to determine pregnant teenagers' readiness for motherhood in the Nkonkobe Municipality. The major findings of this study are that pregnant teenagers' are not ready for motherhood. They showed low levels of performing the roles and responsibilities of motherhood. They displayed negative psychosocial well-being. These findings relate with Erikson's psychosocial theory as the theoretical framework of this study in that , most of the teenage mothers displayed higher levels of parenting stress and less responsive and sensitive in terms of their children's needs. In essence, this is an indication of identity crisis from these teenage mothers.

\subsection{Binary Logistic Results}

A binary logistic regression was used to assess the factors that affect pregnant teenagers' readiness for motherhood.The binary logistic regression model represents choices between two mutually exclusive options; whether pregnant teenagers readiness for motherhood or whether they are not ready for motherhood. In this case, 0 represented pregnant teenagers' readiness for motherhood and 1 which represented pregnant teenagers non- readiness for motherhood.

Equation 1 below represents a general binary logistic regression as follows:

$$
\ln (\mathrm{ODDS})=\ln (\hat{Y} / 1-\hat{Y})=\alpha+\beta_{1} X_{1}+\ldots+\beta_{n} X_{n} \text {. }
$$

Binary logistic results on factors which determine pregnant teenagers' readiness for motherhood in Alice, Nkonkobe Municipality

\begin{tabular}{|l|c|c|}
\hline Variable & Coefficient & Significance P-Value \\
\hline Educational level (pregnant teenager) & $4.769^{\star \star}$ & 0.029 \\
\hline Ready to provide my child's basic needs & $23.047^{\star \star \star}$ & 0.000 \\
\hline I have been taught about maternal challenges & $15.676^{\star \star \star}$ & 0.000 \\
\hline Inclined to respond to my child's needs & $6.485^{\star \star}$ & 0.011 \\
\hline The father of my child supports me financially & $14.292^{\star \star \star}$ & 0.000 \\
\hline The father of my child supports me emotionally & $15.824^{\star \star \star}$ & 0.000 \\
\hline I am self-confident & $10.352^{\star \star \star}$ & 0.001 \\
\hline I talk to my caregiver about My problems & $8.109^{\star \star \star}$ & 0.004 \\
\hline I negotiate safe sex with the father of my child & $6.546^{\star \star}$ & 0.011 \\
\hline
\end{tabular}

Source: Printout of a table derived from the data of this study 
The table above shows the estimated coefficients ( $\beta$ values), and significance values of the predictor or independent variables obtained from use of the binomial logistic regression model. Some predictor variables such aseducational level (of the pregnant teenager), number of siblings, 'readiness to provide my child's basic needs', 'I have been taught about maternal challenges, inclined to respond to my child's needs', 'I plan to raise my child together with the father of my baby',' the father of my child drinks alcohol', 'the father of my child supports me financially', 'the father of my child supports me emotionally','i am self-confident', 'I talk to my caregiver about my problems' and 'I negotiate safe sex with the father of my childinfluenced teenage readiness of motherhood.'

The significant relationship of each demographic variable and teenage motherhood is reflected by $p$-value of less than 0.05 .

Table 6.2: Bivariate Analysis of Relationship between Variables and Motherhood Among Teenagers

\begin{tabular}{|l|c|c|c|c|}
\hline \multirow{2}{*}{ Variable } & \multicolumn{2}{c|}{ Readiness for Motherhood } & \multicolumn{2}{c|}{ Chi square test } \\
\cline { 2 - 5 } & Yes & No & Value & p-value \\
\hline The nutrition of the pregnant teenager & 22 & 84 & 25.625 & ${ }^{\star} 0.002$ \\
\hline Pregnant teenagers' readiness to provide their babies basic needs & 22 & 84 & 45.301 & ${ }^{\star} 0.000$ \\
\hline Pregnant teenagers' knowledge about maternal challenges & 22 & 84 & 31.736 & ${ }^{\star} 0.000$ \\
\hline Pregnant teenagers' readiness to respond to the child/ren needs & 22 & 84 & 61.304 & ${ }^{\star} 0.000$ \\
\hline I am self-confident & 22 & 84 & 40.235 & ${ }^{\star} 0.000$ \\
\hline I talk to my caregiver about my problems & 22 & 84 & 38.409 & ${ }^{\star} 0.000$ \\
\hline I negotiate safe sex with the father of my child & 22 & 84 & 46.906 & ${ }^{\star} 0.000$ \\
\hline My child is my responsibility & 22 & 84 & 27.546 & ${ }^{\star} 0.001$ \\
\hline I plan to raise the child together with the father of my baby & 22 & 84 & 40.403 & ${ }^{\star} 0.000$ \\
\hline
\end{tabular}

Source: Printout of a table derived from the data of this study

The association between level of education of teenagers and motherhood among teenagers was found to be significant with p-value of 0.036 . In most societies in South Africa, teenage motherhood usually occurs before marriage. All can be observed from table 6.2 the proper nutrition of the pregnant teenagers is highly significant with the $p$-value of 0.002 . This indicates that out of 106 pregnant teenagers, only 22 have proper nutrition for the proper growth and development of their babies.

The findings of this study also showed that pregnant teenagers' readiness to provide their babies' basic needs is highly significantly correlated with teenage motherhood and it is reflected by a p-value of 0.000 . This means that out of 106 pregnant teenagers, only 22 are ready to provide their babies basic needs. Drawing from the literature (3.5.1 Socioeconomic status), the findings are that teenage motherhood is characterised by poor socio-economic background. In essence, providing the basic needs for their mothers will be difficult.

The relationship between the teenagers' knowledge about maternal challenges and teenage motherhood is significant with the $p$-value of 0.000 . Bivariate Analysis of Relationship Between Variables and Motherhood Among Teenagers found that out of 106 teenagers only $20.75 \%(N=22)$ had knowledge about maternal challenges contrary to $79.5 \%(\mathrm{~N}=84)$ did not. The findings of the literature (3.5.11 parental skills), showed that most of the teenage mothers are less aware of the maternal challenges and they fall pregnant out of no plan.

\subsection{Findings}

The binary logistic results showed that the following variables / factors: educational level ( teenage mothers), number of siblings, readiness to provide my child's basic needs, I have been taught about maternal challenges, inclined to respond to my child's needs, I plan to raise my child together with the father of my baby, the father of my child drinks alcohol, the father of my child supports me financially, the father of my child supports me emotionally, I am self-confident, I talk to my caregiver about my problems and I negotiate safe sex with the father of my child influenced teenage mothers psychosocial wellbeing for motherhood. This implied that teenage mothers are not psychosocially well for motherhood because their level of awareness for performing the roles and responsibilities for motherhood was very low hence their psycho-social wellbeing was very low as well. 


\section{References}

Babbie, E. and Mouton, J. (2001). The practice of social research. South African edition. Cape Town: Oxford university press.

Baucum, D. (1999). Psychology, Behavioural and Social Sciences. Barron's Educational Series. USA.

Brink, H (2006). Fundamentals of research methodology for health care professionals. 2ndedition.Juta and Co. Cape Town . South Africa.

Burns, N and Grove, S.K. (2005). The practice of nursing research: conduct, critique, and utilization. 5th edition. Elsevier: Saunders.

Chevalier, A and Viitanem, T (2001). Girls Education in South Africa: Teen Mothers schooling challenges. SA.

Compton, WC. and Hoffman, E. (2013). Positive Psychology, the Science of Happiness and Flourishing. Wadsworth Cengage Learning; USA.

Cresswell, J.W. (2011). Educational research : Planning , conducting and evaluating quantitative and qualitative research. International edition. Pearson books. USA.

Desriani ,D (2011). Determinants of teenage motherhood . Evidence of 2007 Indonesia demographic and health survey.

Dryburgh, H. (2002). Teenage pregnancy. Health Reports, 12 (1), 9-18; Statistics Canada.(2005). Health Indicators, 2005, 2. Retrieved from Facts and Statistics: Sexual Health and Canadian Youth - Teen Pregnancy Rates.

Easterbrooks ,M.A., Chaudhuri,J.H., Bartlett,J.D and Copeman, A (2010). Resilience in parenting among young mothers : Family and ecological risks and opportunities. Volume 33. Issue1.Tufts University . USA.

Gustafsson, S. and Worku, S. (2007). Teenage Motherhood and Long-run Outcomes in South Africa. Tinbergen Institute Rotterdam: Netherlands.

Hetherington, E.M, Parke, R.S, Gauvain, M and Locke, V.O. (2006). Child Psychology, A Contemporary Viewpoint. McGraw: New York.

Holborn ,L, and Eddy,G ( (2011). First steps to healing the South African family. A research paper by the South African Institute of race relations sponsored by Donaldson Trust .Marshalltown.

Joseph, J.V (2010). Binary Logistic Regression Analysis. U.S.A.

Kipp,K and Shaffer,D.R (2010). Developmental Psychology,Childhood and Adolescence. International Edition: Wadsworth Cengage Learning. USA.

Leinonen, J.A., Solantaus, T.S., \& Punamaki, R.L (2003). Parent mental health and children's mental health adjustment: the quality of marital interaction and parenting as mediating factors. Journal of child psychology and psychiatry. Volume 44: 227-241.

Lilaroja (2010). Schools 'push teen mothers to be dropouts', Life chances of teenage mothers and their children threatened by barriers to education. Sunday 14 March 2010.

Macleod .J.D. (2000). Journal of Health \& Social Behaviour.Volume 41.No2 .S.A.

Markway, B and Markway, G. (2011). Spreading the word about the value of quiet, sensitive people. September 13th.

Muchuruza, P.P. (2000). Social, economic and cultural factors associated with pregnancy among adolescent girls in Magu District, Mwanza. Unpublished dissertation. Muhimbili University of Health and Allied Sciences.Dar-es-Salaam, Tanzania.

Panday, S., Makiwane, M., Ranchod, C., and Letsoalo, T. (2009).Teenage PREGNANCY IN SOUTH AFRICA.SA.

Papalia, D.E, Olds, S.W. \& Feldman, R.D. (2009). Human - Development .Eleventh Edition. McGraw-Hill Companies, Inc: Boston.

Philemon, M.N, (2007). Factors contributing to high adolescent pregnancy rate in Kinondoni Municipality, Dar-es-salaam, Tanzania, UNISA (University of South Africa).

Planned Parenthood Association of South Africa (1998). Teenage contraceptives needs in urban South Africa. A case study : International Family Planning Perspectives. South Africa.

Ryff,C.D., and Keyes,C.L.M (1995). The structure of psychological well-being revised.Journal of personality and Social psychology, 69 (4), 719-727.

Santrock,J. (2000). Lifespan Development. Mcgraw-Hill. USA

Walliman, N. (2005). International Journal of Social Research Methodology.Volume.9. London.

Weiten, W. (2011). Psychology: Themes and Variations, Brief edition. Wadsworth Cengage Learning. USA.

Weiten, W., Dunn, D.S and Hammer, E.Y (2012). Psychology Applied to modern life: Adjustment in the 21st Century. 10th Edition. Wadsworth Cengage Learning. USA.

Ziyane, I.S. and Ehlers, V.J. (2006). Swazi youth attitudes and perceptions concerning adolescents' pregnancies and contraception. Health S.A. Gesondheid, 11(1):31-42. 